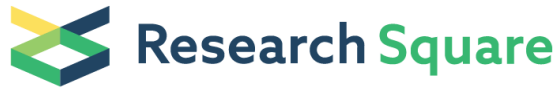 \\ Preprints are preliminary reports that have not undergone peer review. \\ They should not be considered conclusive, used to inform clinical practice, or referenced by the media as validated information.
}

\section{Herpes Simplex Virus 1 and the Risk of Dementia: A Population-Based Study}

\author{
Meghan Murphy \\ Erasmus University Medical Center \\ Lana Fani \\ Erasmus University Medical Center \\ Kamran Ikram \\ Erasmus University Medical Center \\ Mohsen Ghanbari \\ Erasmus University Medical Center \\ Arfan Ikram ( $\square$ m.a.ikram@erasmusmc.nl) \\ Erasmus University Medical Center
}

\section{Research Article}

Keywords: Herpes Simplex Virus 1 (HSV1), dementia, immunoglobulin (IgG)

Posted Date: December 23rd, 2020

DOI: https://doi.org/10.21203/rs.3.rs-125991/v1

License: @ (i) This work is licensed under a Creative Commons Attribution 4.0 International License. Read Full License

Version of Record: A version of this preprint was published at Scientific Reports on April 22nd, 2021. See the published version at https://doi.org/10.1038/s41598-021-87963-9. 


\section{Abstract}

Introduction

Herpes Simplex Virus 1 (HSV1) is a neuroinvasive virus capable of entering the brain which makes it a candidate pathogen for increasing risk of dementia. Previous studies are inconsistent in their findings regarding the link between HSV1 and dementia, therefore, we investigated how HSV1 relates to cognitive decline and dementia risk using data from a population-based study.

\section{Methods}

We measured HSV1 immunoglobulin ( $\mathrm{lgG}$ ) antibodies in serum collected between 2002 and 2005 from participants of the Rotterdam Study. We used linear regression to determine HSV1 in relation to change in cognitive performance during 2 consecutive examination rounds on average 6,5 years apart. Next, we determined the association of HSV1 with risk of dementia (until 2016) using a Cox regression model. We repeated analyses for Alzheimer's disease. All models were adjusted for age, sex, cardiovascular risk factors, and apolipoprotein E genotype.

\section{Results}

Of 1,915 non-demented participants (mean age 71.3 years, 56.7\% women), with an average follow-up time of 9.1 years, 244 participants developed dementia (of whom 203 Alzheimer's disease). HSV1 seropositivity was associated with decline in global cognition (mean difference per standard deviation $-0.16 ; 95 \%$ confidence interval $(95 \% \mathrm{Cl}$ ), $-0.26 ;-0.07$ ), as well as separate cognitive domains, namely memory, information processing, and executive function, but not motor function. Finally, HSV1 seropositivity was not associated with risk of dementia (adjusted hazard ratio, $1.18,95 \% \mathrm{Cl}, 0.83 ; 1.68$ ), similar for Alzheimer's disease.

\section{Discussion}

HSV1 is associated with cognitive decline but not with incident dementia in the general population. These data suggest HSV1 to be associated only with subtle cognitive disturbances but not with greater cognitive disorders that result in dementia.

\section{Introduction}

Dementia is a problem that continues to rise as the elderly population increases, while the exact mechanisms of its cause are unknown. Immunity and inflammation have been implicated as possible pathways in the development of this disease ${ }^{1}$. A potential trigger for an immune response and inflammation is an infection, specifically, caused by Herpes Simplex Virus 1 (HSV1). HSV1 is a neuroinvasive and neurotoxic virus capable of entering the brain via the peripheral nerves, and it is thus a candidate pathogen for increasing dementia risk ${ }^{2,3}$.

HSV1 is highly prevalent worldwide. Once infected, the virus remains latent in the body and can be reactivated throughout a person's lifetime ${ }^{2}$. This constant presence and potential reactivation of the virus has been implicated in the immune response and subsequent development of Alzheimer's disease. ${ }^{4}$ The virus initiates an innate immune system response that causes the production of amyloid beta ${ }^{1}$. The accumulation of amyloid beta due to increased production subsequently causes neuroinflammation. The constant inflammation leads to damage to the brain cells (i.e. neurodegeneration) and eventually could result in dementia. Indeed, we have previously shown that an increase of various innate immune cells, in particular platelets, are associated with an increased risk of dementia in the general population ${ }^{5}$. Previous studies have looked at HSV1 and dementia, although mainly cross-sectionally with inconsistent findings ${ }^{6}$. Hence, there is still a gap in knowledge on how the virus affects the various stages of deteriorating cognition.

In this study, we determined the association of HSV1 with cognitive decline and incident dementia. We hypothesized that HSV1 is associated with poorer (global) cognition and subsequently an increased risk of dementia. 


\section{Methods}

\section{Study Population}

This study was embedded within the Rotterdam Study, a prospective population-based cohort study in Rotterdam, the Netherlands ${ }^{7}$. Within the study there are currently 4 cohorts; however, due to the availability of serum samples for HSV1 measurement this study used the first and second cohorts of the Rotterdam study. The first cohort began in 1990 and the second cohort began in 2000. Both cohorts started with participants of age 55 years or older at baseline. A total of 2,000 randomly selected serum samples, 1,000 from each cohort, were collected at examination rounds between 2002-2005. Baseline for this study was considered the ascertainment date of serum samples from participants (fourth visit for the first cohort, January 2002 through July 2004, and second visit for the second cohort, July 2002 and December 2005). Out of the 2,000 participants, 10 were excluded due to missing HSV1 data because the measurement of antibodies titers was not possible from the plasma samples (e.g., no detectable antibodies or negative viral isolation) and 59 were excluded for missing Apolipoprotein $\mathrm{E}(A P O E)$ carriership. Participants with prevalent dementia were also excluded; therefore, the final study group consisted of 1,915 participants (Fig. 1).

The Rotterdam Study has been approved by the Medical Ethics Committee of the Erasmus MC (registration number MEC 02.1015) and by the Dutch Ministry of Health, Welfare and Sport (Population Screening Act [WBO], license number 1071272159521-PG). The Rotterdam Study personal registration data collection is filed with the Erasmus MC Data Protection Officer under registration number EMC1712001. The Rotterdam Study has been entered into the Netherlands Trial Register (https://www.trialregister.nl) and into the WHO International Clinical Trials Registry Platform (https://www.who.int/ictrp/network/primary/en/) under the shared catalogue number NTR6831. In accordance with the Declaration of Helsinki, all participants provided written informed consent to participate in the study and to have their information obtained from treating physicians.

\section{Assessment of HSV1 antibodies}

The serum samples were collected and centrifuged in EDTA treated containers. The aliquoted plasma was frozen at $-80^{\circ} \mathrm{C}$ based on standard procedures. From the 2,000 serum samples, chemiluminescence immunoassay (CLIA) was done to determine if immunoglobulin $\mathrm{G}$ antibodies (IgG) to HSV1 were present. The DiaSorin LIASION® HSV1/2 IgG assay analyzer gave an index value ranging 0.5 to 30, based on the presence of the antibodies. Samples with an index value below 0.9 were considered negative for the virus. Index values ranging from 0.9 to 1.1 were considered equivocal ${ }^{8}$. Based on these ranges, a dichotomous variable for the virus was created. Values below 1.1 were defined as seronegative, while values of 1.1 and above were defined as seropositive for the HSV1 antibodies.

\section{Assessment of global cognition and cognitive domains}

Participants underwent a battery of cognition tests at the baseline examination visit as well as the next follow-up examination ${ }^{9}$. The tests included Mini Mental State Examination (MMSE), Word Learning Test (WLT immediate and WLT delayed recall), Letter-Digit Substitution Task (LDST), Verbal Fluency Task (VFT), Stroop Test (reading subtask, color naming subtask, and the color-word interference subtask), and Purdue Pegboard Task (PPB). For global cognition, we calculated the gfactor (general cognitive factor) as a standardized compound score using principal component analysis with LDST, Stroop color-word interference subtask, VFT, WLT delayed recall, and PPB sum of both hands. On each test, a higher score indicates a better performance apart from the Stroop test. Data on cognition was collected at baseline and at subsequent examination rounds between 2009-2011 to track cognitive decline.

\section{Assessment of incident dementia and Alzheimer's disease}

Screening for dementia was done at baseline and throughout the study via examination visits and digital medical records. Participants underwent multiple steps before being diagnosed with dementia. The first step was the MMSE and the Geriatric Mental Schedule (GMS). If participants screened positive in either test (MMSE $<26$ or GMS $>0$ ) then it was followed by an examination with the Cambridge Examination for Mental Disorders of the Elderly (CAMDEX) and, if believed to have dementia, 
consequent neuropsychological examinations ${ }^{10}$. Any participant who was unable to visit the center was followed via digital medical records through general practitioners and the Regional Institute for Outpatient Mental Health Care. The final diagnosis was made by a consensus panel in accordance with standard criteria (DSM-III-R) Alzheimer's disease (NINCDS-ADRDA) and vascular dementia (NINDS-AIREN) ${ }^{11,12}$. Follow-up was until January 1, 2016 with $95.5 \%$ of participants. Participants were censored at date of dementia diagnosis, death, or loss to follow-up.

\section{Covariates}

Potential confounding variables were chosen based on previous literature ${ }^{10}$. Data on sex, age, and prevalent diseases were obtained at each examination visit. Information on smoking, alcohol consumption, and education was collected through interview. Body mass index (BMI) was calculated by weight in kilograms divided by height in meters squared. We grouped blood pressure and cholesterol into two categorical covariates, hypertension and hypercholesterolemia, due to the large number of covariates. Measurement of blood pressure was done while participants were in a sitting position with a randomzero sphygmomanometer. The average was taken from two measurements. Hypertension was then found if blood pressure was over $\geq 140 / 90 \mathrm{mmHg}$ or if the participant was taking blood pressure lowering medication. Cholesterol and high-density lipoprotein ( $\mathrm{HDL}$ )-cholesterol were collected in serum through an automated enzymatic procedure, the Boehringer Mannheim System. Hypercholesterolemia was categorized as having high cholesterol levels (>6.2 mmol/L) or use of lipid lowering medication. APOE genotype was found via serum sample. Additional information from the serum samples was collected on high sensitivity C-reactive protein (hs-CRP) and platelet count.

\section{Statistical Analysis}

The continuous values of HSV1 IgG antibodies were standardized. We used both the continuous and the dichotomous values of HSV1 antibodies in the models. All models were corrected for sub cohort, sex, and age at baseline. We additionally adjusted for BMI, smoking, alcohol consumption, education, hypercholesterolemia, hypertension, APOE genotype, coronary heart disease, diabetes mellitus, and stroke, all measured at baseline.

The Stroop reading subtask scores were log transformed, the Stroop color naming and color-word interference subtask scores were square root transformed. In addition, the Stroop subtask scores were inverted by multiplying with - 1 to better match the other cognitive tests. All cognitive test results were standardized. Linear regression analysis was done for each cognition test performed during the fifth examination visit as outcome variable and the baseline (fourth examination visit) cognition test scores were adjusted for in the model. First the g-factor and MMSE were analyzed after which we explored each test separately.

A Cox regression analysis was performed to study the association between HSV1 and incident dementia and Alzheimer's disease (AD). For incident dementia, we performed a sensitivity analysis using varying cutoffs for seroprevalence to assess effects of varying antibody levels (index value of cutoffs for seroprevalence: 0.7 to 1.4 with 0.1 increment increase). In addition, we performed stratification to assess effect modification and calculated multiplicative interaction by age (10-year intervals), sex, hs-CRP (threshold: $>2 \mathrm{mg} / \mathrm{L}$ ), APOE- 44 carrier status, and platelet levels (based on the median; threshold: $>252 \times 10^{9}$ per liter $)^{5}$. Interactions by hs-CRP and platelet levels were analyzed to check whether a higher innate immunity status affected the link of HSV1 with dementia compared to having a lower innate immunity status.

The assumptions for linear regression and Cox regression were checked for all analyses. Missing data was imputed 5 times using multiple imputation by chained equations (MICE) using the outcome and covariates as predictors to impute missing covariates, pooling the 5 imputations. All analyses were completed using IBM SPSS Statistics version 25.0 (IBM Corp., Armonk NY).

\section{Results}

The baseline characteristics of the study population are in Table 1. The mean age at baseline was 71.3 years $( \pm 7.5)$. Of 1915 participants, 1518 were HSV1-seropositive (79.3\%). 
Table 1

Baseline Characteristics of the Study Population

\begin{tabular}{|c|c|c|}
\hline Characteristics & $\begin{array}{l}\text { Cohort undergoing cognitive examination* } \\
(\mathrm{N}=1249)\end{array}$ & $\begin{array}{l}\text { Dementia-free cohort } \\
(\mathrm{N}=1915)\end{array}$ \\
\hline Females & $719(57.6 \%)$ & $1086(56.7 \%)$ \\
\hline Age, years & $69.0 \pm 6.3$ & $71.3 \pm 7.5$ \\
\hline \multicolumn{3}{|l|}{ Cohort } \\
\hline First & $671(45.7 \%)$ & $928(48.5 \%)$ \\
\hline Second & $678(54.3 \%)$ & $900(50.3 \%)$ \\
\hline \multicolumn{3}{|l|}{ Education } \\
\hline Primary education & $95(7.7 \%)$ & $203(10.7 \%)$ \\
\hline Lower/intermediate general education & $546(44.1 \%)$ & $849(44.8 \%)$ \\
\hline Intermediate vocational education & $382(30.9 \%)$ & $564(29.7 \%)$ \\
\hline Higher vocational education & $214(17.3 \%)$ & $281(14.8 \%)$ \\
\hline \multicolumn{3}{|l|}{ Apolipoprotein E4ع carriership } \\
\hline Non-carrier $(\varepsilon 2 / \varepsilon 2, \varepsilon 2 / \varepsilon 3$ or $\varepsilon 3 / \varepsilon 3)$ & 918 (73.5\%) & $1398(73.0 \%)$ \\
\hline Carrier $(\varepsilon 4 / \varepsilon 4, \varepsilon 3 / \varepsilon 4$ or $\varepsilon 2 / \varepsilon 4)$ & $331(26.5 \%)$ & $517(27.0 \%)$ \\
\hline \multicolumn{3}{|l|}{ Smoking } \\
\hline Current & $171(13.9 \%)$ & $270(14.3 \%)$ \\
\hline Former & $692(56.1 \%)$ & $1053(55.7 \%)$ \\
\hline Never & $370(30.0 \%)$ & $568(30.0 \%)$ \\
\hline Body mass index, $\mathrm{kg} / \mathrm{m}^{2}$ & $27.7 \pm 3.9$ & $27.6 \pm 4.1$ \\
\hline Hypertension & $913(73.1 \%)$ & $1485(77.5 \%)$ \\
\hline Hypercholesterolemia & $607(51.2 \%)$ & $900(47.2 \%)$ \\
\hline Alcohol consumption & $12.7 \pm 14.1$ & $12.1 \pm 14.7$ \\
\hline History of coronary heart disease & $108(8.7 \%)$ & 206 (10.9\%) \\
\hline Diabetes mellitus type 2 & $142(11.6 \%)$ & $279(15.2 \%)$ \\
\hline History of stroke & $35(2.8 \%)$ & $78(4.1 \%)$ \\
\hline
\end{tabular}

Abbreviations: $\mathrm{N}$, number of participants included in study. Data presented as mean (standard deviation) for continuous variables and number (percentages) for categorical variables. Data represent original data without imputed values.

*Participants underwent multiple cognitive tests.

Of 1900 participants (99.6\%) who underwent detailed cognitive assessment at baseline, 1249 (65.4\%) had repeated assessment at follow-up (mean interval 6.5 years). Within HSV1 seropositive participants, the mean difference in g-factor score was lower by 0.16 (95\% confidence interval [95\% Cl]: - $0.26 ;-0.07)$ compared to HSV1 seronegative participants. Per standard deviation (SD) increase in HSV1 antibody titer the mean difference in g-factor [z-score] was $-0.04(-0.08 ; 0.002)$. For MMSE, the mean difference in Z-score for HSV1 seropositive participants compared to seronegative participants was lower by $0.12(-0.24 ; 0.002)$ compared to seronegative participants and per SD increase in HSV1 antibody titer $-0.06(-0.11 ;-0.01)$. 
HSV1 was significantly associated with several cognitive tests. WLT delayed had the largest difference with a z-score mean difference of $-0.12(-0.24 ; 0.004)$ for HSV1 seropositive compared to HSV1 seronegative. Seropositive HSV1 was associated with decreased z-scores in LDST. HSV1 seropositive was significant in both the VFT $(-0.13,-0.24 ;-0.03)$ and the LDST $(-0.12$, $-0.21 ;-0.04)$ compared to seronegative participants. Results were similar for HSV1 antibody titer. Neither HSV1 seropositivity nor HSV1 antibody titer showed a significant decrease in the PPB Sum test (Table 2).

Table 2

Association of serum HSV1 titer with Cognitive Decline in the Rotterdam Study

\begin{tabular}{|c|c|c|c|c|c|c|c|c|c|c|}
\hline \multicolumn{11}{|c|}{ Mean change in cognition in standard deviation $(95 \% \mathrm{Cl})$} \\
\hline & $\begin{array}{l}\text { G- } \\
\text { factor }\end{array}$ & MMSE & $\begin{array}{l}\text { WLT } \\
\text { Immediate }\end{array}$ & $\begin{array}{l}\text { WLT } \\
\text { Delayed }\end{array}$ & $\begin{array}{l}\text { Stroop: } \\
\text { Reading }\end{array}$ & $\begin{array}{l}\text { Stroop: } \\
\text { Color } \\
\text { Naming }\end{array}$ & $\begin{array}{l}\text { Stroop: } \\
\text { Color- } \\
\text { Word }\end{array}$ & LDST & VFT & PPB \\
\hline & $\begin{array}{l}n= \\
901\end{array}$ & $\begin{array}{l}n= \\
1249\end{array}$ & $n=1091$ & $\begin{array}{l}n= \\
1091\end{array}$ & $\begin{array}{l}n= \\
1154\end{array}$ & $\begin{array}{l}n= \\
1152\end{array}$ & $\begin{array}{l}n= \\
1145\end{array}$ & $\begin{array}{l}n= \\
1159\end{array}$ & $\begin{array}{l}n= \\
1193\end{array}$ & $\begin{array}{l}n= \\
1029\end{array}$ \\
\hline \multirow{2}{*}{$\begin{array}{l}\text { HSV1 serum } \\
\text { seroprevalence }\end{array}$} & -0.16 & -0.12 & -0.03 & -0.12 & -0.10 & -0.08 & -0.11 & -0.12 & -0.13 & -0.09 \\
\hline & $\begin{array}{l}(-0.26 \\
-0.07)\end{array}$ & $\begin{array}{l}(-0.24 \\
0.002)\end{array}$ & $\begin{array}{l}(-0.14 \\
0.09)\end{array}$ & $\begin{array}{l}(-0.24 \\
0.004)\end{array}$ & $\begin{array}{l}(-0.21 \\
0.01)\end{array}$ & $\begin{array}{l}(-0.19 \\
0.04)\end{array}$ & $\begin{array}{l}(-0.23 \\
0.01)\end{array}$ & $\begin{array}{l}(-0.21 \\
-0.04)\end{array}$ & $\begin{array}{l}(-0.24 \\
-0.03)\end{array}$ & $\begin{array}{l}(-0.19 ; \\
0.01)\end{array}$ \\
\hline \multirow{2}{*}{$\begin{array}{l}\text { HSV1 serum } \\
\text { IgG antibody } \\
\text { titer }\end{array}$} & -0.04 & -0.06 & -0.02 & -0.07 & -0.04 & -0.02 & -0.02 & -0.04 & -0.05 & -0.02 \\
\hline & $\begin{array}{l}(-0.08 \\
0.002)\end{array}$ & $\begin{array}{l}(-0.11 \\
-0.01)\end{array}$ & $\begin{array}{l}(-0.07 \\
0.03)\end{array}$ & $\begin{array}{l}(-0.12 \\
-0.02)\end{array}$ & $\begin{array}{l}(-0.08 \\
0.01)\end{array}$ & $\begin{array}{l}(-0.06 \\
0.03)\end{array}$ & $\begin{array}{l}(-0.07 \\
0.03)\end{array}$ & $\begin{array}{l}(-0.08 \\
-0.01)\end{array}$ & $\begin{array}{l}(-0.10 \\
-0.01)\end{array}$ & $\begin{array}{l}(-0.06 ; \\
0.03)\end{array}$ \\
\hline
\end{tabular}

The Stroop subtask scores were inverted to better match the other cognitive tests. In addition, the Stroop reading subtask scores were log transformed, the Stroop color naming and color-word interference subtask scores were square root transformed. All cognitive test results were standardized. Linear regression analysis was done for each cognition test performed during the fifth examination visit as outcome variable and the baseline (fourth examination visit) cognition test scores were adjusted for in the model.

Abbreviations: MMSE, Mini Mental State Examination; WLT, Word Learning Test; LDST, Letter-Digit Substitution; VFT, Verbal Fluency Test; PPB, Purdue Pegboard Test: Sum of Both Hands.

Note: Linear Regression Model adjusted for sub cohort, sex, age, body mass index, smoking, alcohol consumption, education, hypertension, hypercholesterolemia, apolipoprotein E carrier status, coronary heart disease, diabetes mellitus, and stroke.

During an average follow-up time of 9.1 years $( \pm 3.4), 244$ participants were diagnosed with dementia, 203 of whom were diagnosed with Alzheimer's disease. HSV1 seropositivity was not associated with a higher risk of all-cause dementia (adjusted hazard ratio [HR] of 1.18 (95\% Cl: 0.83; 1.68)). Per SD increase of antibody titer of HSV1, the HR was $1.03(0.90 ; 1.17)$. For Alzheimer's disease, the results were similar for HSV1 seropositive and HSV1 antibody titer (1.13, 95\% Cl: $0.77 ; 1.66$ and 1.05, 95\% Cl: 0.90; 1.21, respectively) (Table 3). 
Table 3

Association of serum HSV1 titer with Incident Dementia in the Rotterdam Study

\begin{tabular}{|c|c|c|c|c|c|c|}
\hline & \multicolumn{3}{|c|}{ Hazard Ratio of dementia (95\% Cl) } & \multicolumn{3}{|c|}{$\begin{array}{l}\text { Hazard Ratio of Alzheimer's } \\
\text { Disease }(95 \% \mathrm{Cl})\end{array}$} \\
\hline & $\mathrm{n} / \mathrm{N}$ & Model I & Model II & $\mathrm{n} / \mathrm{N}$ & Model I & Model II \\
\hline HSV1 serum IgG seronegative & $38 / 397$ & reference & reference & $32 / 397$ & reference & reference \\
\hline HSV1 serum IgG seropositive & 206/1518 & $\begin{array}{l}1.21 \\
(0.86 \\
1.72)\end{array}$ & $\begin{array}{l}1.18 \\
(0.83 \\
1.68)\end{array}$ & $171 / 1518$ & $\begin{array}{l}1.18 \\
(0.80 \\
1.72)\end{array}$ & $\begin{array}{l}1.13 \\
(0.77 \\
1.66)\end{array}$ \\
\hline $\begin{array}{l}\text { HSV1 serum IgG antibody titer per standard } \\
\text { deviation increase }\end{array}$ & 244/1915 & $\begin{array}{l}1.06 \\
(0.93 \\
1.20)\end{array}$ & $\begin{array}{l}1.03 \\
(0.90 \\
1.17)\end{array}$ & 203/1915 & $\begin{array}{l}1.08 \\
(0.94 \\
1.25)\end{array}$ & $\begin{array}{l}1.05 \\
(0.90 \\
1.21)\end{array}$ \\
\hline
\end{tabular}

Abbreviations: HR, hazard ratio; $\mathrm{Cl}$, Confidence Interval; n, number of cases; N, number of subjects; IgG, immunoglobulin $\mathrm{G}$.

NOTE: Cox Model I, adjusted for sub cohort, sex, and age. Cox Model II, adjusted for sub cohort, sex, age, body mass index, smoking, alcohol consumption, education, hypertension, hypercholesterolemia, apolipoprotein carrier status, coronary heart disease, diabetes mellitus, and stroke.

The different cut-off levels for HSV1 seroprevalence showed similar results (Figure S1). Seropositive males had a larger hazard ratio of dementia than seropositive females $(1.56,95 \% \mathrm{Cl}: 0.84 ; 2.90$ and $1.06,95 \% \mathrm{Cl}: 0.69 ; 1.63$, respectively), although the multiplicative interaction between sex and HSV1 seropositive was not significant. The hazard ratio for HSV1 seroprevalent dementia cases varied widely between age groups, with the interaction term for age and HSV1 seroprevalence being significant $(p=0.034)$. The highest age category, 88-98 years old, was not analyzed due to lack of power. The group with higher hs-CRP levels (>2 mg/L) had a higher hazard ratio for seroprevalence (HR 1.66) compared to the group with lower hs-CRP levels (HR 1.05), with the multiplicative interaction between the virus and CRP being borderline significant $(p=0.180)$. The group with higher platelet levels ( $>252 \times 10^{9}$ per liter), had a higher HR of $1.32(95 \% \mathrm{Cl}: 0.78 ; 2.26)$ compared to lower platelet levels for the seropositive group (HR 1.07), however we observed no significant interaction. APOE- 44 carriers had no effect change for HSV1 seropositivity (Fig. 2). All assumptions were met for all analyses.

\section{Discussion}

In this study, cognitive decline was more pronounced in HSV1 seropositive compared to seronegative participants in global cognition and the cognitive domains of memory, information processing and executive function ${ }^{13}$. There was no association between HSV1 and the development of dementia.

The current literature mainly focuses on the final stage of deteriorated cognition: dementia ${ }^{6}$ and only few studies have investigated cognition ${ }^{12,13}$. In the studies that found an association between declined cognition and HSV, it was only with high infectious burden, i.e. multiple viruses (a combination of HSV1, HSV2, and Cytomegalovirus) ${ }^{14}$ or in carriers of $A P O E-\varepsilon 4^{15}$. One study found no association between HSV1 and cognitive decline ${ }^{16}$.

Previous studies found conflicting results regarding the association between HSV1 and dementia ${ }^{6}$. Two previous cohort studies varied from our cohort in having a shorter follow-up time (the longest being 4 years), which makes these studies more prone to reverse causation ${ }^{17,18}$, In a Taiwanese retrospective cohort study they found an association, but all the HSV cases included in the study were more virulent infections requiring anti-viral medication which may have resulted in stronger effects $^{19}$. Another study only saw the association in $A P O E-\varepsilon 4$ carriers ${ }^{20}$, unlike our study. In one of the few longitudinal studies on the subject, an association was found only with HSV1 immunoglobulin M (IgM) antibodies and AD but not with HSV1 IgG antibodies and AD (HR: $0.99,95 \% \mathrm{Cl}: 0.57 ; 1.72)^{21}$ which is consistent with our study. Another study looking at HSV IgG 
antibodies and dementia revealed a HR of $1.67(95 \% \mathrm{Cl}: 0.75 ; 3.73)^{22}$, yet both of these studies failed to differentiate between HSV1 and HSV2 antibodies. A third prospective cohort study studying the same association found a HR of 0.77 (95\% Cl: 0.58 ; 1.04) for HSV1 specific IgG antibodies ${ }^{23}$. It is possible that the presence of HSV1 IgG antibodies does not lead to constant inflammation; therefore, the latent virus is not associated with greater cognitive disturbances. Since our study comprised the general population, a high prevalence of latent HSV1 was expected as opposed to a reactivated infection.

A potential mechanism for an HSV1 infection to affect cognition is via a temporary production of amyloid beta to repress the infection. This leads to short-lived inflammation which affects cognition according to the recent antimicrobial protection hypothesis of $A D^{1}$. Once the infection and subsequent inflammation are gone, cognition is no longer impaired.

In our study, the HSV1 infection as measured by IgG antibodies (latent infection) are associated with a subtle decrease in global cognition over time. Due to lack of information on cognition tests at later examination dates (after 2011) in our study, we do not know whether cognition stayed at the new decreased level or if it returned to the previous level measured at baseline. However, our results suggest that it did not decrease further; otherwise, we would have observed an association between HSV1 and dementia. The combination of multiple neurotoxic viruses may be required to cause permanent damage to cognitive function, therefore HSV1 alone is not enough to see a significant effect.

A major strength of this study was the availability of prospectively collected data and the length of follow-up time. In addition, we were able to analyze both the subtle (i.e. cognition) and large changes in cognition (i.e. dementia) in one study.

It is also important to consider the limitations of this study. A major one is the availability of only HSV1 IgG antibodies which only gave us information on infection prior to baseline. Without data on the HSV1 IgM, we were unable to tell whether the participants had an active HSV1 infection at baseline. Since the reactivation of the virus is the proposed pathway to deteriorating cognition, we would need to investigate HSV1 IgM antibodies and each stage of deteriorating cognition to gain a better understanding. Another limitation is the lack of generalizability as the Rotterdam Study cohort predominantly consists of Caucasian participants living in a middle-income area in Rotterdam.

In conclusion, HSV1 is associated with a decrease in global cognition and cognitive domains, but not with dementia risk in the general population. These findings suggest that HSV1 IgG antibodies may lead to subtle cognitive disturbances but not greater cognitive disorders.

\section{Declarations}

\section{Acknowledgments}

We gratefully acknowledge the study participants of the Ommoord district and their general practitioners and pharmacists for their devotion in contributing to the Rotterdam Study. We also thank all staff that facilitated assessment of participants in the Rotterdam Study throughout the years.

This work was supported by the European Union's Horizon 2020 research and innovation programme [grant number 667375] ("CoSTREAM"); the Erasmus Medical Center and Erasmus University Rotterdam; the Netherlands Organization for Scientific Research (NWO) [grant numbers 948-00-010, 918-46-615]; the Netherlands Organization for Health Research and Development (ZonMw); The Research Institute for Diseases in the Elderly (RIDE); the Ministry of Education, Culture and Science; the Ministry of Health, Welfare and Sports; the European Commission (DG XII); and the Municipality of Rotterdam.

The funding source had no role in study design, collection, analysis, interpretation of data, writing of the report or decision to submit the article for publication.

\section{Conflicts of interest}


none

\section{References}

1. Moir RD, Lathe R, Tanzi RE. The antimicrobial protection hypothesis of Alzheimer's disease. Alzheimer's Dement. 2018;14(12):1602-1614. doi:10.1016/j.jalz.2018.06.3040

2. Whitley RJ, Roizman B. Herpes simplex virus infections review. Lancet. 2001;357:1513-1518. doi:10.1016/S01406736(00)04638-9

3. Mori I, Nishiyama Y, Yokochi T, Kimura Y. Olfactory transmission of neurotropic viruses. J Neurovirol. 2005;11(2):129-137. doi:10.1080/13550280590922793

4. Itzhaki RF. Herpes simplex virus type 1 and Alzheimer's disease: Increasing evidence for a major role of the virus. Front Aging Neurosci. 2014;6(AUG):1-9. doi:10.3389/fnagi.2014.00202

5. van der Willik, Kimberly D.; Fani, Lana; Rizopoulos, Dimitris; Licher, Silvan; Fest, Jesse; Schagen, Sanne B.; Ikram, M. Kamran; Ikram MA. Balance between innate versus adaptive immune system and the risk of dementia : a populationbased cohort study. 2015:1-9.

6. Warren-Gash C, Forbes HJ, Williamson E, et al. Human herpesvirus infections and dementia or mild cognitive impairment: a systematic review and meta-analysis. Sci Rep. 2019;9(1):1-10. doi:10.1038/s41598-019-41218-w

7. Ikram MA, Brusselle G, Ghanbari M, et al. Objectives, Design and Main Findings until 2020 from the Rotterdam Study. Vol 35. Springer Netherlands; 2020. doi:10.1007/s10654-020-00640-5

8. DiaSorin. LIAISON® HSV-1/2 IgG (REF 310800). 2016;(Vc):1-9. www.diasorin.com.

9. Hoogendam YY, Hofman A, Van Der Geest JN, Van Der Lugt A, Ikram MA. Patterns of cognitive function in aging: The Rotterdam Study. Eur J Epidemiol. 2014;29(2):133-140. doi:10.1007/s10654-014-9885-4

10. de Bruijn RFAG, Bos MJ, Portegies MLP, et al. The potential for prevention of dementia across two decades: The prospective, population-based Rotterdam Study. BMC Med. 2015;13(1):1-8. doi:10.1186/s12916-015-0377-5

11. Associaton AP. Diagnostic and Statistical Manual of Mental Disorders. DSM-III-R. Arlingto, VA: American Psychiatric Association; 1987.

12. Licher S, Darweesh SKL, Wolters FJ, et al. Lifetime risk of common neurological diseases in the elderly population. $J$ Neurol Neurosurg Psychiatry. 2019;90(2):148-156. doi:10.1136/jnnp-2018-318650

13. Wolters FJ, Zonneveld HI, Hofman A, et al. Cerebral perfusion and the risk of dementia: A population-based study. Circulation. 2017;136(8):719-728. doi:10.1161/CIRCULATIONAHA.117.027448

14. Strandberg TE, Pitkala K, Eerola J, Tilvis R, Tienari PJ. Interaction of herpesviridae, APOE gene, and education in cognitive impairment. Neurobiol Aging. 2005;26(7):1001-1004. doi:10.1016/j.neurobiolaging.2004.09.008

15. Lövheim H, Norman T, Weidung B, et al. Herpes Simplex Virus, APOE €4, and Cognitive Decline in Old Age: Results from the Betula Cohort Study. J Alzheimer's Dis. 2019;67(1):211-220. doi:10.3233/JAD-171162

16. Nimgaonkar VL, Yolken RH, Wang T, et al. Temporal cognitive decline associated with exposure to infectious agents in a population-based, aging cohort. Alzheimer Dis Assoc Disord. 2016;30(3):216-222. doi:10.1097/WAD.0000000000000133

17. Agostini S, Mancuso R, Baglio F, et al. High avidity HSV-1 antibodies correlate with absence of amnestic Mild Cognitive Impairment conversion to Alzheimer's disease. Brain Behav Immun. 2016;58:254-260. doi:10.1016/j.bbi.2016.07.153

18. Aiello AE, Haan MN, Blythe L, Moore K, Gonzalez JM, Jagust W. The influence of latent viral infection on rate of cognitive decline over 4 years. J Am Geriatr Soc. 2006;54(7):1046-1054. doi:10.1111/j.1532-5415.2006.00796.x

19. Tzeng NS, Chung CH, Lin FH, et al. Anti-herpetic Medications and Reduced Risk of Dementia in Patients with Herpes Simplex Virus Infections-a Nationwide, Population-Based Cohort Study in Taiwan. Neurotherapeutics. 2018;15(2):417429. doi:10.1007/s13311-018-0611-x

20. Itzhaki RF, Lin W, Shang D, Wilcock GK, Faragher B, Jamieson GA. Herpes simplex virus type 1 in brain and risk of Alzheimer's disease. 1997;349:1-4. 
21. Lövheim H, Gilthorpe J, Adolfsson R, Nilsson LG, Elgh F. Reactivated herpes simplex infection increases the risk of Alzheimer's disease. Alzheimer's Dement. 2015;11(6):593-599. doi:10.1016/j.jalz.2014.04.522

22. Letenneur, Luc, Garrigue I, Barberger-gateau P, Pe K, Helmer C, Orgogozo J, Gauthier S. Seropositivity to Herpes Simplex Virus Antibodies and Risk of Alzheimer' s Disease: A Population-Based Cohort Study. 2008;3(11):1-5. doi:10.1371/journal.pone.0003637

23. Torniainen-Holm M, Suvisaari J, Lindgren M, Härkänen T, Dickerson F, Yolken RH. The lack of association between herpes simplex virus 1 or Toxoplasma gondii infection and cognitive decline in the general population: An 11-year follow-up study. Brain Behav Immun. 2019;76(October 2018):159-164. doi:10.1016/j.bbi.2018.11.016

\section{Figures}

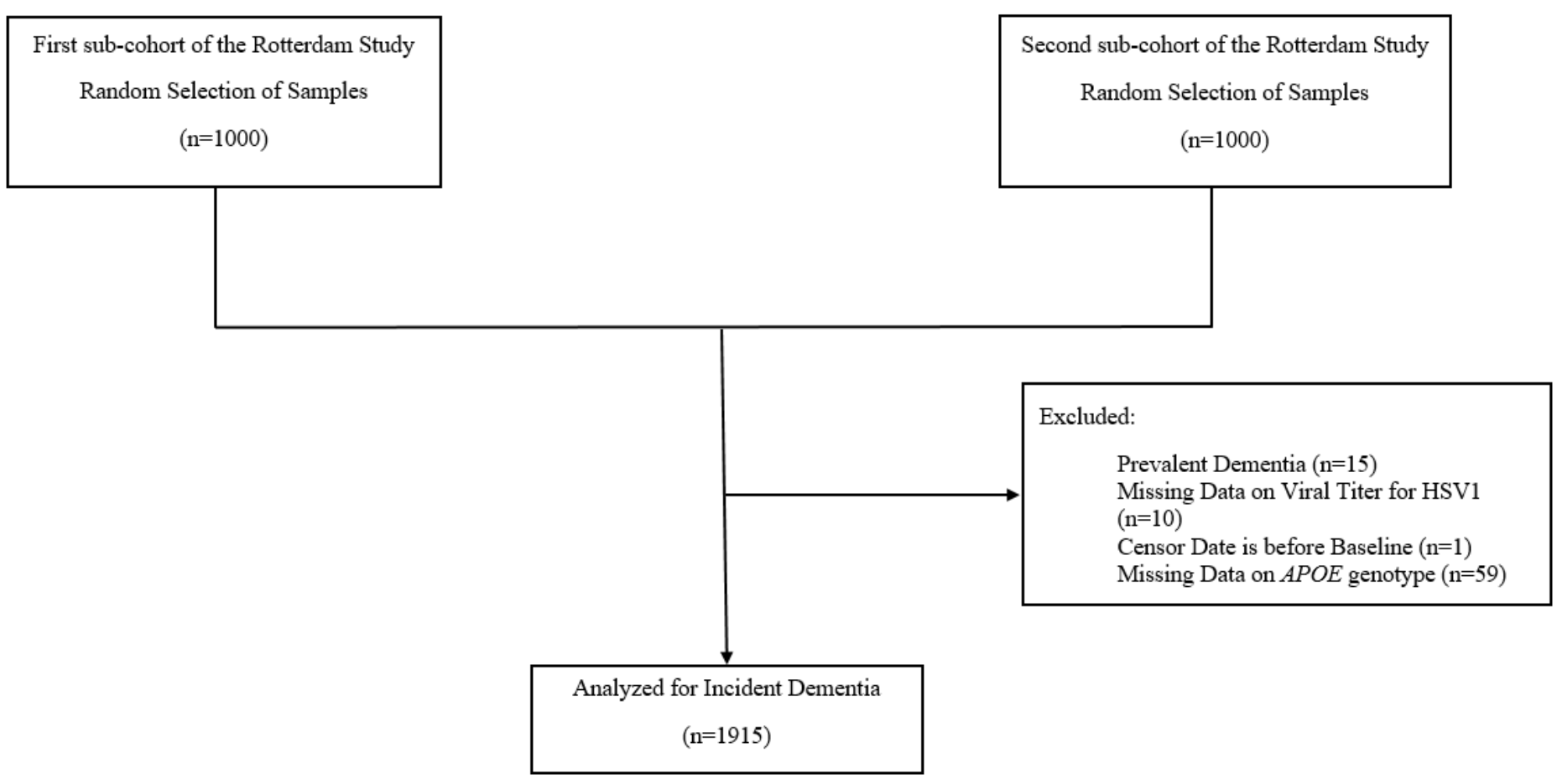

\section{Figure 1}

Flowchart for Selection of Participants for Incident Dementia Analysis 
Risk of Dementia

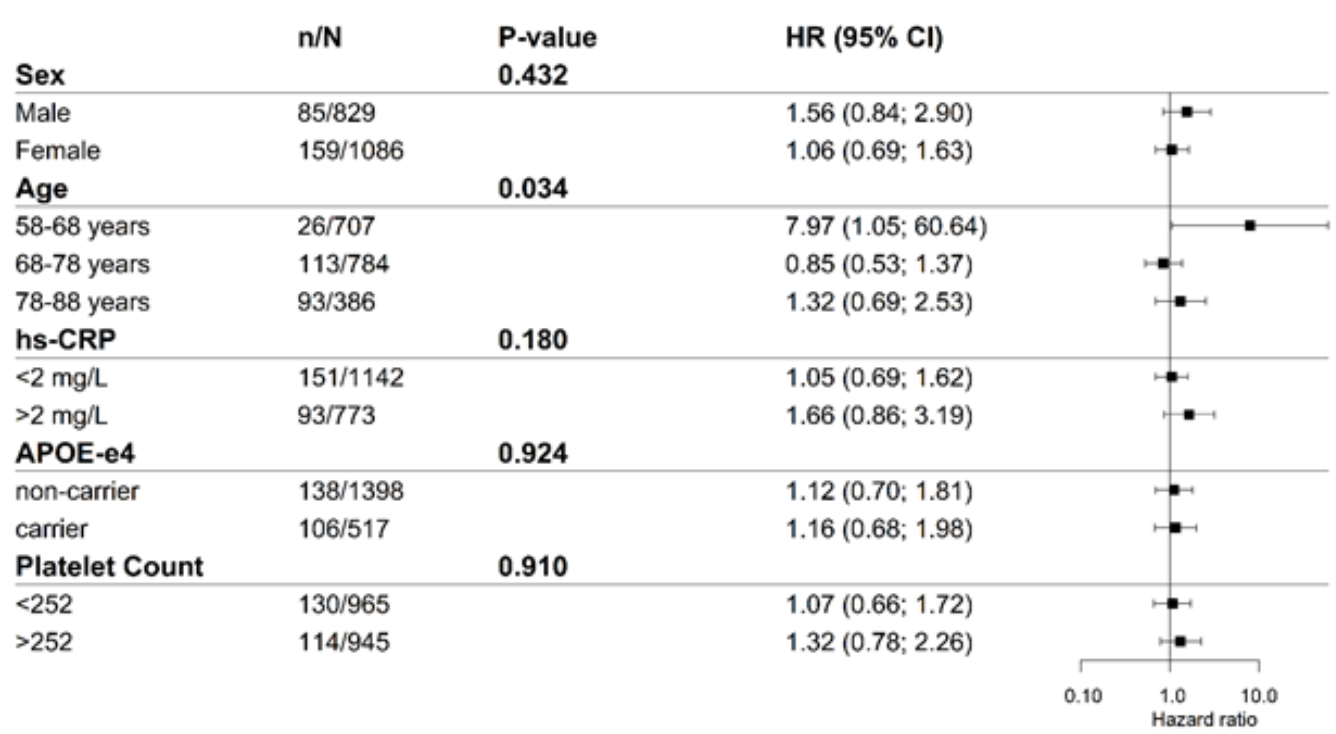

Figure 2

Stratification of Various Factors for the Relation of serum HSV1 titer to the Risk of Dementia Note: $n / N$ represents the number of dementia cases. P-value is for the interaction term of the grouping variable and seroprevalence HSV1. Abbreviations: HR, hazard ratio of incident dementia; $\mathrm{Cl}$, confidence interval.

\section{Supplementary Files}

This is a list of supplementary files associated with this preprint. Click to download.

- SUPPLEMENTS.pdf 